\title{
AMBIVALÊNCIAS \\ O Nordeste nas obras de Gilberto Freyre e Celso Furtado
}

\section{Rejane Calazans}

O Nordeste não é só isso. Em off, esta declaração abre uma vinheta televisiva, enquanto aparece uma imagem de terra ressecada, visivelmente carente de chuva. Ao corte desse cenário, segue-se uma seqüência de imagens para mostrar que o Nordeste é uma região onde se consomem produtos variados, apresentando cenas de fluxos de pessoas em lojas. ${ }^{1}$ A intenção é atrair investimentos para a região, mostrar que ela não se esgota na miséria, ao contrário, por detrás da imagem da seca existe uma economia viva e dinâmica. No entanto, um Nordeste não exclui o outro, isto é, o movimento da economia não exclui a estagnação da seca. Estagnação e movimento dão um duplo sentido à região.

Muitas imagens são evocadas quando se menciona a região Nordeste, evidenciando a plu-

Artigo recebido em dezembro/2005

Aprovado em dezembro/2006 ralidade de significados construídos em torno dela. Em consonância com a seca, pensa-se em pobreza, miséria, violência, coronelismo, messianismo. Em contraste com a seca, vêm à lembrança imagens de paisagens e eventos turísticos, como o Pelourinho de Salvador, as praias de Fortaleza, o Bumba-meuBoi do Maranhão, enfim, abundância, exuberância, prazeres. Apesar de contrastantes, essas visões do Nordeste convivem lado a lado, de uma forma ambivalente.

Ao pensar nessas ambivalências, a abordagem proposta por Zygmunt Bauman configurase como uma importante chave analítica. De acordo com esse autor, a ambivalência decorre de uma das principais funções da linguagem, qual seja, a de nomear e classificar (Bauman, 1999). Podem-se considerar dois níveis de manifestação da ambivalência na região Nordeste. Um decorre do esforço de classificação do Brasil em regiões, estabelecendo a relação entre o Nordeste e as demais regiões do país, especialmente em oposição ao Sul 
e ao Sudeste. O outro é interno, ou seja, a conjugação de elementos contraditórios dentro de uma mesma região - elementos como miséria e opulência, seca e fartura, violência e sociabilidade harmoniosa, sertão e litoral.

Essa convivência de elementos contraditórios é construída e consolidada de diversas formas - como nas imagens veiculadas pela televisão -, além de assegurar um lugar privilegiado para o Nordeste no pensamento social brasileiro. Trata-se de um olhar de extrema acuidade, que tenta explicar suas especificidades, o por quê da pobreza e da miserabilidade, a razão de sua riqueza cultural. A resposta não significa apenas um diagnóstico da situação regional, mas também, e sobretudo, uma explicação para o Brasil, seja na perspectiva do atraso econômico, seja do ponto de vista da diversidade cultural.

Celso Furtado e Gilberto Freyre foram dois dos mais importantes pensadores brasileiros que se dedicaram a pensar o Nordeste, e suas visões da região refletem, de fato, suas concepções do Brasil. Gilberto Freyre enfatizou a "civilização do açúcar", ou seja, o litoral do Nordeste; Celso Furtado, por sua vez, centrou suas análises no sertão nordestino. À primeira vista, os Nordestes apresentados por esses autores são espaços geográficos que se opõem. No entanto, mais do que espaços geográficos, suas concepções refletem espaços sociais.

\section{Gilberto Freyre e o Nordeste}

O Nordeste de Gilberto Freyre é o que se desenvolveu a partir da região açucareira. Mas o autor reconhecia que a região não se reduzia a isto:

A palavra "nordeste" é hoje uma palavra desfigurada pela expressão "obras do Nordeste" que quer dizer: "obras contra as secas". E quase não sugere senão as secas. Os sertões de areia seca rangendo debaixo dos pés. Os sertões de paisagens duras doendo nos olhos. Os mandacarus. Os bois e os cavalos angulosos. As sombras leves como umas almas do outro mundo com medo do sol (Freyre, 1989, p. 41).

No entanto, dando seguimento à citação, o autor apresenta o Nordeste que será seu objeto de reflexão:
Mas esse Nordeste de figuras de homens e de bichos se alongando quase em figuras de $\mathrm{El} \mathrm{Greco}$ é apenas um lado do Nordeste. O outro Nordeste. Mais velho que ele é o Nordeste de árvores gordas, de sombras profundas, de bois pachorrentos, de gente vagarosa e às vezes arredondada quase em sanchos-panças pelo mel de engenho, pelo peixe cozido com pirão, pelo trabalho parado e sempre o mesmo, pela opilação, pela aguardente, pela garapa de cana, pelo feijão de coco, pelos vermes, pela erisipela, pelo ócio, pelas doenças que fazem a pessoa inchar, pelo próprio mal de comer terra (Idem, ibidem).

Gilberto Freyre já alertava, pois, para a existência de dois Nordestes: um de árvores gordas e sombras profundas, e outro da seca e da miséria. Com efeito, observamos aí a convivência de elementos opostos numa clara manifestação de ambivalência. Freyre justamente evocava a ambivalência contida na palavra, , reconhecendo, inclusive, que Nordeste não se resumia a essas duas imagens:

Aliás há mais de dois Nordeste e não um, muito
menos Norte maciço e único de que se fala tanto
no Sul com exagero de simplificação. As especia-
lizações regionais de vida, de cultura e de tipo físi-
co no Brasil estão ainda por ser traçadas debaixo
de um critério rigoroso de ecologia ou sociologia
regional, que corrija tais exageros e mostre que
dentro da unidade essencial, que nos une, há
diferenças, às vezes profundas (Idem, p. 42).

A região foi pensada por Gilberto Freyre não como um espaço determinado pelos elementos físicos, mas como um espaço social. Isso foi explicitado pelo autor no prefácio a Casa grande $\mathcal{E}$ senzala, ao afirmar ser o espaço social ocupado pelo sistema patriarcal da lavoura açucareira condicionado por elementos geológicos, botânicos e físico-geográficos, mas, de forma alguma, determinado por eles. Seu ponto de vista era de que o sistema patriarcal com suas formas constantes e processos incessantes, sua ação e sua dinâmica, foi superior a todos os elementos físicos - tropicais ou quase tropicais (Freyre, 2001).

A região açucareira, para o autor, foi onde melhor se expressou o sistema patriarcal de colonização portuguesa no Brasil, representado pela casa-grande, complementada pela senzala. Mas 
Freyre generaliza essa idéia, no sentido de que daí se formou todo um sistema econômico, social e político. Em outras palavras, foi em torno dos senhores de engenho que se construiu o tipo de civilização mais estável da América Hispânica. Assim, a casa-grande, embora associada particularmente ao engenho da cana-de-açúcar e ao patriarcalismo nordestino, não deveria ser considerada exclusiva da economia açucareira, uma vez que o sistema patriarcal se estendeu a toda monocultura escravista e latifundiária, tornandose a tradução mais profícua do caráter social brasileiro (Idem).

Gilberto Freyre definiu a sociedade patriarcal como sendo um luxo de antagonismos. Luxo que, por outro lado, não deixava de constituir antagonismos em equilíbrio, em que os excessos despontavam em cada aspecto da vida colonial (Lima, 2001). Ao aproximar visões diferentes, até antagônicas, sem dissolvê-las (Araújo, 2001), Freyre afirmou que a civilização patriarcal continha sinais de mais e de menos, ou seja, era uma sociedade que comportava oposições geradas em sua própria base, a monocultura, elemento primordial para qualquer esforço de interpretação social, e mesmo psicológica, do Nordeste agrário (Freyre, 1989).

O perfil da região é o perfil de uma paisagem enobrecida pela capela, pelo cruzeiro, pela casagrande, pelo cavalo de raça, pelo barco a vela, pela palmeira imperial, mas deformada ao mesmo tempo pela monocultura latifundiária e escravocrática; esterilizada por ela em algumas de suas fontes de vida e de alimentação mais valiosas e mais puras; devastadas nas suas matas; degradadas nas suas águas (Idem, p. 18).

Ao mesmo tempo em que deformou as fontes de vida naturais, a cana adoçou a vida social. No prefácio de Açúcar, livro de receitas publicado por Gilberto Freyre, ele afirma que, além da influência direta do açúcar sobre a comida, a cozinha, as tradições portuguesas de bolo e de doce, o açúcar influenciou indiretamente as maneiras e os gestos, adoçando-os assim como às palavras, ao adoçar a própria língua portuguesa (Freyre, 1997). Trata-se, portanto, de um processo ambivalente, em que deformação e criação não se excluem.
O Nordeste que Gilberto Freyre abordou em sua obra não era apenas um recorte naturalista da região, mas um espaço social. Era um ethos, cuja base foi a civilização açucareira e seu ponto de maior intensidade, Pernambuco. Os valores culturais que se desenvolveram a partir desse centro se espalharam por todo o Brasil e não se restringiram cronologicamente a um determinado período de nossa história.

É importante frisar que Gilberto Freyre não era apenas um pesquisador do modo de viver nordestino, mas se apresentava como portador desse ethos, alguém que tinha legitimidade suficiente para clamar para um revigoramento dos valores da região, como o fez no Manifesto regionalista (Freyre, 1952). Ao tentar tornar o ethos nordestino algo vivo, ele fabricou imagens de Nordeste que se confundiam à sua própria imagem, o que fica evidente com a publicação do seu diário (Freyre, 1975), em que a vivência e a memória do autor são apresentadas ao público. Dessa forma, Freyre tornou-se o principal idealizador do discurso sobre a brasilidade nordestina, que erigiu a região como uma marca da originalidade brasileira.

\section{Celso Furtado e a transformação do Nordeste}

A infância no Nordeste marcou profundamente Celso Furtado, que lembrava da região como um mundo marcado pela violência e arbitrariedade, uma sociedade estratificada e parada no tempo (Furtado, 1997a)

Foi na indústria açucareira que, segundo ele, se originou a sociedade nordestina. O rápido desenvolvimento dessa indústria, apesar das dificuldades do meio físico, indicava claramente a concentração do esforço do governo português na produção da cana-de-açúcar. Isso ficava patente também nos privilégios que eram concedidos pela Coroa portuguesa aos donatários, como honrarias, títulos e isenções de tributos (Furtado, 2001).

A capacidade de a unidade exportadora açucareira preservar sua estrutura determinou sua persistência. A economia açucareira do Nordeste resistiu por mais de três séculos a prolongadas depressões, recuperando-se sempre que as con- 
dições do mercado externo permitiam, não sofrendo nenhuma modificação estrutural significativa (Idem, ibidem).

Apesar de centrar sua análise no sertão, para Celso Furtado a sociedade nordestina originou-se na indústria açucareira, o que caracterizou o início da colonização portuguesa na América no século XVI. O incentivo português ao cultivo da cana-de-açúcar e o mercado de dimensões relativamente grandes possibilitaram que se formasse um sistema econômico de alta produtividade e em rápida expansão na faixa litorânea do Nordeste brasileiro. Esse sistema necessariamente acarretou conseqüências diretas e indiretas para as demais regiões do subcontinente que eram reivindicadas pelos portugueses. Dessa forma, "mesmo aquelas comunidades que aparentemente tiveram um desenvolvimento autônomo nessa etapa da colonização, deveram sua existência indiretamente ao êxito da economia açucareira" (Idem, p. 41).

A própria expansão da economia açucareira fomentou a formação de um setor suplementar de apoio, com a criação de animais, sobretudo o gado de corte e de tiro. Mas logo se evidenciou que era impraticável criar gado na faixa litorânea, isto é, dentro das unidades produtoras de açúcar (Idem). As terras interioranas, na região semi-árida do Nordeste, foram, então, ocupadas para suprir a carência por animais de tração e proteína alimentar. Quando o pólo exportador crescia, a demanda por insumos provenientes desse setor periférico, evidentemente, se expandia; mas não só isso, a economia periférica não parou de crescer, ainda que houvesse oscilações no setor exportador, pois o essencial de sua produção era autoconsumido, e a disponibilidade de terras era considerável. Ou seja, criou-se uma estrutura capaz de resistir às oscilações da demanda. E foi a separação dessas duas atividades econômicas - a açucareira e a de criação - que deu lugar ao surgimento de uma economia dependente no interior da região nordestina (Idem).

Com efeito, Celso Furtado aplicou o modelo centro-periferia, elaborado pelas teses da Cepal - Comissão Econômica para a América Latina e o Caribe -, no interior do Nordeste. A Cepal inaugurou nos anos de 1950 a reflexão sobre as economias que passaram a ser conheci- das como subdesenvolvidas. Centro-periferia foi o conceito empregado para descrever o processo técnico na economia mundial e para explicar a distribuição de seus ganhos. De acordo com essa idéia, a divisão internacional do trabalho provocou, desde os primeiros estágios do capitalismo industrial, efeitos diferenciados na economia mundial, que cresceu de forma também diferenciada em termos de estágio de desenvolvimento. Ou seja, o desenvolvimento econômico na região central produzia o subdesenvolvimento na periferia (Moraes, 1995).

A região semi-árida era, então, a periferia da faixa litorânea. A influência da economia litorânea na região semi-árida deu-se em duas vertentes, segundo Celso Furtado. De um lado, criou a demanda por criação de animais; de outro, gerou uma oferta de pessoal capacitado para promover a ocupação territorial. Assim, a ocupação do semi-árido nordestino realizou-se com pequeno esforço financeiro e centrou-se, desde o início, na pecuária extensiva, o que constituiu a base da organização socioeconômica, em vez de ser simples complemento da atividade agrícola.

A sociedade periférica que emergiu na zona semi-árida tinha como traço característico a dispersão espacial dos camponeses, que dependiam totalmente dos proprietários de terras. Nesse contexto, o trabalhador rural não dispunha de meios para acumular riqueza, o que resultava num endividamento cada vez maior. Conseqüentemente, a população trabalhadora dessa região estava condenada ao imobilismo, isto é, reproduzir o passado de forma mecânica (Furtado, 1997).

Celso Furtado demonstrou que as formas assumidas pelos dois sistemas da economia nordestina - o açucareiro e o de criação - se constituíram em elementos fundamentais na formação do que viria a ser a economia brasileira no século XX, quando a região Centro-Sul emergiu como centro econômico e as disparidades regionais foram acentuadas com o avanço da industrialização (Furtado, 2001). Para o autor, um sistema industrial de base regional não podia coexistir dentro de um mesmo país com um conjunto de economias primárias dependentes e subordinadas, pois as relações econômicas entre uma economia industrial e economias primárias tendiam sempre a formas de exploração. Esta era a 
base ideológica da Operação Nordeste, um plano político direcionado à região, iniciado durante o governo de Juscelino Kubitschek sob a direção de Celso Furtado, e de onde se originou a Sudene Superintendência de Desenvolvimento do Nordeste (Furtado, 1959).

A Sudene pretendia ser um órgão de natureza renovadora com o objetivo de dar ao governo um instrumento que o capacitasse a formular uma política unificada de desenvolvimento para o Nordeste. Um dos pontos primordiais para essa nova formulação política foi a seca (Idem). A partir da seca de 1877, o governo federal passou a implementar as frentes de trabalho no Nordeste, que tenderam a se proliferar nos períodos de seca. Para Celso Furtado, esse tipo de ação do governo reforçava o status quo existente. O quadro de fome criado pela seca não era percebido como decorrente de decisões tomadas pela classe dirigente, reflexo de uma estrutura social que estava sendo reforçada pela ação governamental. A Sudene propunha reverter esse quadro, distanciando-se dos tradicionais esquemas de enfeudação que cercavam os órgãos governamentais da região (Furtado, 1997).

Furtado acreditava que era preciso uma intervenção planejada na região de forma a acabar com a injustiça social, a violência e a miséria; e a Sudene representava, para ele, a realização desta possibilidade.

\section{Últimas palavras}

As visões de Nordeste elaboradas por Celso Furtado e Gilberto Freyre reafirmam que a seca não elimina a fartura, mas convive com ela. Essa é a manifestação mais clara da ambivalência interna apontada na discussão proposta por este trabalho. A ambivalência resulta em uma sensação de indecisão, de irresolução e, portanto, de perda de controle. No entanto, é importante frisar que falar em sensação de indecisão é diferente de indecisão. Diferença que decorre do fato de a indecisão implicar sempre na possibilidade de escolha, o que não ocorre no campo da ambivalência, onde caracteres diferentes coexistem, sendo que um não elimina o outro. E é justamente essa sensação de indecisão, em que a escolha não é possível, que acarreta os sentimentos de irresolução e de perda de controle. Uma forma de suprimir tal sentimento seria a busca por uma situação de equilíbrio, em que as oposições coexistissem em harmonia (Bauman, 1999). Gilberto Freyre propunha justamente uma harmonização entre o rural e o urbano, evitando desequilíbrios ambientais. Essa perspectiva socioecológica concretizar-se-ia em uma política rurbana, que equilibraria os valores urbanos e rurais não apenas no Nordeste, mas no Brasil como um todo (Freyre, 1987).

Uma outra forma de eliminar aquela sensação de indecisão seria a busca incessante pela ordem, suprimindo e eliminando tudo que não fosse precisamente definido. Trata-se de uma prática tipicamente moderna. $\mathrm{O}$ horror à mistura e a obsessão pela separação impulsionam o processo de fragmentação do mundo, resultando em uma dicotomia que cria a ilusão de simetria ao representar seus membros como iguais e intercambiáveis. Mas a própria existência dessa dicotomia já é testemunho da presença de um poder diferenciador, classificador (Bauman, 1999).

De acordo com essa argumentação, a dicotomia inerente ao conceito centro-periferia é uma ferramenta primordial do modelo de análise elaborado pela Cepal e encontra-se claramente perceptível na obra de Celso Furtado, quando ele aplica tal modelo à realidade brasileira. Ao refletir sobre o processo de formação da economia brasileira, Celso Furtado percorreu a trajetória de desenvolvimento desigual no Brasil, que fez com que a região Centro-Sul emergisse como centro dinâmico do país (Furtado, 2001).

Cada um a seu tempo e com uma perspectiva própria, Gilberto Freyre e Celso Furtado realizaram uma incursão pela ambivalência presente na região Nordeste. O primeiro propôs uma abordagem socioecológica, que promovesse o equilíbrio entre contrários. O segundo, por sua vez, pretendia dissolver o atraso econômico e social que opunha o Nordeste ao Centro-Sul desenvolvido, mediante uma intervenção planejada na região.

$\mathrm{Na}$ abordagem de Freyre, era preciso uma restauração dos valores culturais do verdadeiro Nordeste, um retorno ao passado, que se realizaria no futuro. Nessa idéia também está implícita a busca por características que poderiam diferenciar o Brasil como nação, no sentido de 
arrefecer a visão do país pautada em modelos europeus.

$\mathrm{Na}$ abordagem de Furtado, uma intervenção planejada transformaria o Nordeste em uma região desenvolvida, mediante um projeto de desconcentração regional de renda, a superação do arcaísmo da estrutura fundiária, a apropriação e o uso improdutivo do excedente rural pelos grandes proprietários fundiários, a reforma agrária; em suma, a justiça social. E o futuro do Brasil como nação dependeria de tal transformação

Em contraponto à abertura deste artigo, poderíamos dizer: "O Nordeste não é só isso". Mas o Nordeste também é isso. Identidade plural, que abrange concepções já consolidadas, como as de Celso Furtado e Gilberto Freyre, o Nordeste está certamente aberto a novas formulações.

\section{Nota}

1 Estas são imagens que compõem um comercial veiculado pela Rede Globo.

\section{BIBLIOGRAFIA}

ARAÚJO, Ricardo Benzaquen de. (1994), Guerra e paz: casa-grande E senzala na obra de Gilberto Freyre nos anos 30. Rio de Janeiro, Editora 34.

BAUMAN, Zygmunt. (1999), Modernidade e ambivalência. Rio de Janeiro, Jorge Zahar Editor.

FREYRE, Gilberto. (1952), Manifesto Regionalista de 1926. Recife, Região.

(1975), Tempo morto e outros tempos: trechos de um diário de adolescência e primeira mocidade (1915-1930). Rio de Janeiro, José Olympio.

. (1987), Rurbanização-que é. Recife, Massapé.

(1989), Nordeste. 6 ed. Rio de Janeiro, Record.

. (1997), Açúcar: uma sociologia do doce, com receitas de bolos e doces do
Nordeste. São Paulo, Companhia das Letras.

. (2001), Casa-grande E senzala. 45 ed. Rio de Janeiro, Record.

FURTADO, Celso. (1959), A operação Nordeste. Rio de Janeiro, Instituto Superior de Estudos Brasileiros.

. (1997), "A fantasia desfeita", in - Obra autobiográfica de

Celso Furtado, tomo II, São Paulo, Paz e Terra.

(1997a), "Aventuras de um economista brasileiro", in — Obra autobiográfica de Celso Furtado, tomo II, São Paulo, Paz e Terra.

. (2001), Formação econômica do Brasil. São Paulo, Companhia Editora Nacional.

LIMA, Luiz Costa. (1994), "Apresentação", in Ricardo Benzaquen de Araújo, Guerra e paz: casa-grande \& senzala na obra de Gilberto Freyre nos anos 30, Rio de Janeiro, Editora 34.

MORAES, Reginaldo. (1995), Celso Furtado e o subdesenvolvimento e as idéias da Cepal. São Paulo, Ática. 


\section{AMBIVALÊNCIAS: O NOR- DESTE NAS OBRAS DE GIL- BERTO FREYRE E CELSO FUR- TADO}

Rejane Calazans

Palavras-chave

Brasil; Nordeste; Gilberto Freyre; Celso Furtado; Ambivalência

A região Nordeste ocupa um lugar privilegiado no pensamento social brasileiro sendo vista ora como local da originalidade, ora como o local do atraso, ora como ambos. E esta convivência entre características aparentemente opostas atribui um caráter ambivalente à região. Este artigo reflete sobre as concepções de Nordeste presentes nas obras de Gilberto Freyre e Celso Furtado.

\section{AMBIVALENCES: NORTHEAST- ERN BRAZIL IN THE WORKS OF GILBERTO FREYRE AND CELSO FURTADO}

Rejane Calazans

\section{Keywords}

Brazil; Northeast; Celso Furtado; Gilberto Freyre; Ambivalence.

The Northeastern region occupies a privileged space in the Brazilian social thought; sometimes as the place of originality, sometimes as the place of decay, sometimes both. And this coexistence among apparently opposite features confers an ambivalent character to the region. This article reflects on the Northeastern conceptions in the works of Gilberto Freyre and Celso Furtado.
AMBIVALENCES: LE NORDESTE DANS LES CEUVRES DE GILBERTO FREYRE ET CELSO FURTADO

Rejane Calazans

\section{Mots-clés}

Brésil; Nordeste; Gilberto Freyre; Celso Furtado; Ambivalence.

La région Nordeste occupe une place privilégiée dans la pensée sociale brésilienne. Elle est soit considérée comme un endroit de grande richesse culturelle, soit comme la manifestation de retard économique et social. Elle peut même être considérée suivant ces deux perspectives. La familiarité de caractéristiques apparemment opposées imprime un caractère ambivalent à la région. Cet article propose une réflexion sur les conceptions de Nordeste présentes dans les ouvres de Gilberto Freyre et de Celso Furtado. 